\title{
O PROJETO HEGELIANO DE UMA FILOSOFIA LIVRE DE PRESSUPOSIÇÕES
}

\author{
Federico Orsini* \\ platoniet@yahoo.it
}

RESUMO $O$ objetivo de meu trabalho é o esclarecimento de quatro características distintivas do sistema hegeliano como projeto de uma filosofia livre de pressuposições. Para tanto, pretendo reconstruir a conexão entre os seguintes traços constitutivos do conceito operativo de Voraussetzungslosigkeit (ausência de pressuposição): em primeiro lugar, a imanência do real ao pensar objetivo; em segundo, a integração do ceticismo pirrônico ou antigo ao modo de apresentação científica do pensar; em terceiro lugar, a configuração do elemento lógico em termos de um movimento de circulação de si mesmo; em quarto, a subversão da compreensão ordinária da dupla conceitual "abstrato-concreto". A reconstrução assim oferecida permite argumentar sobre conclusões relevantes para compreender adequadamente a ambição do projeto especulativo de Hegel: em primeiro lugar, a ausência de pressuposições só pode confirmar-se enquanto prova cientifica por meio da subversão das certezas arraigadas no senso comum; em segundo, a prova da imanência é científica na medida em que mostra o necessário entrelaçamento do aspecto ontológico com o aspecto epistemológico do sistema, tornando-o invulnerável a objeções céticas de tipo radical; em terceiro, o sistema não é de modo algum reduzível à estrutura da Enciclopédia, pois essa é apenas um auxílio didático para a apresentação do sistema, cujo significado verdadeiro pode ser atingido unicamente pela organização cada vez mais concreta dos silogismos da ideia da filosofia.

Palavras chave: Sistema, Imanência, Pensar, Ceticismo, Abstrato, Concreto.

* PUCRS. Artigo recebido em 24/11/2016 e aprovado em 12/01/2017. 
Abstract: The aim of my article is the clarification of four distinctive characters of Hegel's system as a project of a presuppositionless philosophy. For this purpose, I will reconstruct the connection among the following features of the operative concept of presuppositionlessness: in the first place, the immanence of the real in the objective thinking; in the second place, the integration of pyrrhonian or ancient skepticism into the scientific way of presentation of thinking; in the third place, the configuration of the logical element in terms of an inner circulation; in the fourth place, the subversion of the ordinary understanding of the couple 'abstract-concrete'. This reconstruction allows me to argue for some conclusions relevant for the understanding of the ambitions of the Hegelian speculative project. In the first place, presuppositionlessness can be confirmed as a scientific proof only if the subversion of the commonsensical distinctions between abstract and concrete succeeds. In the second place, the proof of the immanence is scientific insofar as it shows the necessary intertwinement of the ontological aspect with the epistemological aspect of the system, making it invulnerable to radical skeptical objections. In the third place, the system is by no means reducible to the structure of the Encyclopedia, since this is only a didactic support for the presentation of the system, whose true meaning can be attained only by the more and more concrete organization of the syllogisms of the idea of philosophy.

Keywords: System, Immanence, Thinking, Skepticism, Abstract, Concrete

\section{Introdução}

Como se sabe, o único problema que ocupou a fase madura da filosofia de Hegel foi o de conferir à filosofia a forma de ciência, precisamente daquela que o $§ 5$ da primeira versão (1817) da Enciclopédia chama de ciência da liberdade, em que a liberdade constitui tanto o objeto quanto o sujeito da ciência. Boa parte das interpretações mais recentes e influentes do idealismo hegeliano é marcada por um viés pragmatista, assumido como remédio para a oscilação entre dois extremos igualmente indesejados: de um lado, o espectro de uma metafísica dogmática, tomada caricaturalmente como a "visão da totalidade das coisas enquanto super-mente autorreferencial, cujos pensamentos não precisam e não podem ir além de si mesmos"'; de outro lado, o perigo de uma 
filosofia analítica ${ }^{2}$ saturada que, apesar do orgulho de considerar a si mesma como a única forma respeitável de praticar a filosofia, acaba muitas vezes sendo esterilmente enclausurada na torre de marfim de sofisticações abstratamente formais, cuja base material continua inalteradamente a ser providenciada pelo empirismo crasso do senso comum ou pelo naturalismo decorrente do modelo de saber das ciências naturais.

O propósito do presente trabalho não é o de comentar sobre as virtudes ou os limites de uma específica interpretação pragmatista de Hegel, mas o de dar um passo para trás do palco do debate contemporâneo, com vistas a reconstruir teoricamente, de uma forma interna ao entendimento do próprio Hegel, os quatro marcos distintivos de sua original concepção da Voraussetzungslosigkeit (ausência de pressuposição), a qual, para o filosofo alemão, tem de caracterizar o único critério de verdade da filosofia enquanto ciência:

1. Imanência da realidade ao pensar: o pensar é em e para si, na medida em que não é primacialmente a propriedade de algum tipo de consciência, mas a "razão (Vernunft) daquilo que é"3.

2. Integração de ceticismo ao momento dialético da racionalidade.

3. Apresentação do elemento lógico na forma de um movimento circular.

4. Subversão da oposição do senso comum entre abstrato e concreto.

A tese geral aqui defendida é a de que a assim chamada "metafísica" hegeliana ${ }^{4}$ é, a rigor, uma teoria peculiar do pensar objetivo, cujo método de apresentação é a Voraussetzungslosigkeit. Conforme a abordagem que será proposta, unicamente a busca pela problematização das relações teórico-práticas entre formas de saber e suas respectivas pressuposições é o esforço que hoje pode oferecer a construção de um molde metafilosófico capaz de viabilizar, ao nível particularizado das linhas de pesquisa, uma interlocução crítica com

2012. p. 145-166, p. 162.

2 Por "filosofia analítica" entendo aqui, de modo bastante livre e amplo, um conjunto de diversas correntes filosóficas, que vão do atomismo lógico de Russell ao contextualismo de Wittgenstein, da filosofia da linguagem ordinária ao pragmatismo analítico (isto é, o pragmatismo americano mediado pela tradição "continental" do empirismo lógico). Para uma tentativa de desafiar a aparência monolítica sugerida pelo rótulo "filosofia analítica" a partir de uma reconstrução de suas vertentes históricas e da dissolução de seu mito anti-hegeliano de origem, leia-se: NUZZO, A. (Org.). "Hegel and the Analytic Tradition". New York: Continuum, 2009, especialmente pp. 1-11. O livro mais recente e significativo sobre a reviravolta hegeliana na filosofia analítica é: REDDING, P. "Analytic Philosophy and the Return of Hegelian Thought”. Cambridge: Cambridge University Press, 2007. Para uma resenha do referido livro de Redding, voltada a mostrar quais seriam os elementos do idealismo de Hegel que o tornariam susceptível de uma apropriação pela tradição analítica, remeto a: BRANDOM, R. "Some Hegelian Ideas of Note for Contemporary Analytic Philosophy", Hegel Bulletin, v. 35, n. 1, pp. 1-15, 2014.

3 Cf. HEGEL, G. W. F. Ciência da lógica. A doutrina do ser”. Petrópolis: Vozes, 2016. p. 40.

4 Para uma cuidadosa análise das razões pelas quais o sistema hegeliano não pode ser visto apenas como a morte da metafísica, mas também como o lugar de sua transfiguração, recomendo: CHIEREGHIN, F. Mort et transfiguration de la métaphysique chez Hegel. In: Kervégan, J. F.; Mabille, B. (Orgs.). "Hegel au présent. Une releve de la métaphysique?" Paris: CNRS Éditions, 2012. pp. 51-64. 
o pragmatismo analítico sobre os temas mais candentes do debate contemporâneo: a convicção de que o pensar seria uma atividade sujeita a normas, cuja fonte estaria na síntese social de padrões de reconhecimento recíproco, a deflação do alcance metafísico do idealismo em direção a formas de falibilismo epistêmico e semântico, a integração e a subordinação da teoria às exigências práticas de reprodução de uma sociedade de tipo moderno, a investigação dos métodos e das motivações de um estudo racional das categorias que estruturam nosso agir e nosso falar.

\section{Idealismo absoluto como projeto de uma filosofia livre de pressu- posições}

Uma vez que, para Hegel, a ciência é uma maneira peculiar daquela atividade que ele denomina "pensar", convém determo-nos sobre o significado que o termo "pensar" obtém dentro de uma concepção que se propõe dissolver qualquer abordagem (filosófica ou não) que assuma previamente, ou acabe involuntariamente por consolidar, a contraposição entre mente e mundo.

Antes de mais nada, é preciso indicar em que consiste a irredutibilidade do pensar. O pensar não é primariamente um processo psicológico, ainda que Hegel reconheça como um fato (quer dizer, como algo de não originário, possível de ser explicado a partir de uma origem não fatual) que o pensar também exista como fenômeno psicológico. Se o pensar fosse reduzido a semelhante fenômeno, a distinção sistemática entre Lógica e Psicologia na Enciclopédia perderia sua razão de ser. Além disso, o pensar não é primariamente uma ferramenta que os seres humanos podem usar à vontade para aplicá-lo à satisfação de necessidades irrefletidas, supostamente externas ao pensar, embora a própria noção de instrumento e a existência efetiva de qualquer ferramenta tornemse possíveis, para Hegel, somente graças à racionalidade do pensar ${ }^{6}$. Sobre a pretensa instrumentalidade do pensar, o segundo Prefácio (1831) oferece uma crítica explícita à presunção inerente à assim chamada lógica natural, isto é, à ideia de que, na vida cotidiana, nós somos os que dispõem das categorias, não vice-versa: a visão adequada, para Hegel, é a de que, no âmbito da vida comum, as categorias são determinações universais que agem por trás das costas

5 Cf. HEGEL, G. W. F. "Enciclopédia das Ciências Filosóficas em Compêndio (1830), Vol. I, A Ciência da Lógica”. São Paulo: Edições Loyola, 1995, §2, p. 40: “[E]nquanto a filosofia é uma maneira peculiar de pensar, uma maneira pela qual o pensar se torna conhecer e conhecer conceituante, seu pensar terá também uma diversidade em relação ao pensar ativo em tudo o que é humano, [pensar] que até mesmo efetua a humanidade do humano, embora seja idêntico a esse pensar e em si só seja um pensar" (Tradução modificada).

6 Para um aprofundamento da análise hegeliana do instrumento enquanto momento fundamental (termo médio) do silogismo objetivo da racionalidade técnica do trabalho, remeto o leitor especialmente ao capítulo sobre a Teleologia na seção "Objetividade" da Doutrina do Conceito (1816) da Ciência da Lógica. 
da consciência dos agentes. Mas em geral, o pensar não pode ser reduzido a um posit, isto é, ao produto de qualquer substrato material ou de qualquer prática supostamente heterogênea ou anterior ao pensar, porque a distinção entre produto e atividade é interna ao próprio pensar. Caso contrário, toda a tentativa hegeliana de assumir a tarefa do espinosismo, a fim de entender a substância como conceito (isto é, como logos que compreende a si mesmo) e de fazer deste o círculo dinâmico de imanência absoluta da efetividade, encontrar-se-ia equivocado por inteiro.

A razão pela qual tanto uma abordagem mentalista quanto uma abordagem pragmática ao tema "O que significa pensar?" acabam sendo presas a objeções céticas de tipo radical ${ }^{7}$ é, a meu ver, que ambas não se recusam a, de algum modo, localizar o pensamento, tornando-o o espaço de intervenção de um ente específico, o qual, em virtude de uma habilidade que o caracteriza, definir-seia em contraste com determinados âmbitos objetivos, os quais estariam direta ou indiretamente (isto é, através de um mundo intermediário, o mundo daquilo que Frege nos acostumou a chamar de mundo do sentido, no qual o sentido seria o modo de apresentação daquilo a que o pensamento se refere) em algum tipo de relação causal, ativa ou passiva, com o mundo do pensar subjetivo.

O pensar por si mesmo não pode pertencer a um mundo, pois cada mundo é algo finito e fechado em si, enquanto o pensar tem de prestar conta da constituição do conceito de mundo e, além disso, da possibilidade real e da existência de qualquer mundo que venha a se apresentar. A ideia de que o pensar tenha de dar conta (no duplo sentido de fornecer tanto a ratio essendi quanto a ratio cognoscendi de algo) do conceito de mundo e, ao mesmo tempo, da possibilidade, efetividade e necessidade do objeto correspondente ao conceito em questão, poderia chocar a sensibilidade filosófica de qualquer um que tome por garantida a validade de distinções (ou até dicotomias) clássicas do criticismo kantiano, especialmente aquela entre âmbito conceitual e âmbito não conceitual, a qual remete àquela entre pensar (entendido como capacidade de fazer uso puramente lógico de conceitos) e conhecer, entendido como uso real dos conceitos em vista da elaboração de um âmbito material da experiência, cuja existência não pode ser, em última instância, reconduzida à autoatividade (Selbsttätigkeit) do pensar.

Sem poder aqui entrar no mérito dos fundamentos da crítica hegeliana ao criticismo kantiano $^{8}$, limito-me a destacar dois aspectos decisivos da infinitude

7 Por "objeções céticas de tipo radical" entendo aquelas reconduzíveis ao Trilema de Agripa (com referência ao cético grego do mesmo nome), segundo o qual todas as tentativas de fundamentar nossas pretensões de verdade (em nosso caso, pretensões de verdade sobre o pensar) acabam esbarrando em um ou no outro dos seguintes problemas: (i) regresso infinito das premissas; (ii) escolha arbitrária de um princípio; (iii) circularidade viciosa entre fundamento e fundado.

8 Remeto a uma recente contribuição de Ferrarin, que identifica e discute criticamente três premissas da lei- 
do pensar. Em primeiro lugar, a infinidade significa que o pensar não está de antemão restrito a qualquer tipo de estrutura, nem que seja a da referência de representações subjetivas a contextos de objetos empiricamente identificáveis. Em segundo lugar, a infinidade não deve ser entendida como um mero termo de contraste com o finito, ainda menos pode ser hipostasiada como um fundamento transcendente que existiria de modo separado do finito. A infinitude é, antes, um processo afirmativo, que tem sua gênese lógica a partir da dissolução interna do ponto de vista da finitude (inclusa a oposição entre sujeito e objeto). A infinitude é essencialmente potência de ser e, portanto, tem a ver com o princípio de um automovimento, não com um espaço ideal a ser relacionado, por um lado, com o espaço supostamente finito de nossas representações e práticas e, por outro lado, com o espaço causal e mecânico de uma natureza desprovida de subjetividade.

Se colocamos a pergunta sobre como Hegel argumenta a favor de uma concepção neoespinosana da infinidade, podemos descobrir que o elo teórico capaz de unir o ceticismo a respeito de dogmatismos de várias espécies e a exposição sistemática do pensar infinito é o conceito operativo de Voraussetzungslosigkeit (ausência de pressuposição) ${ }^{9}$. Minha tese geral é a de que o elemento lógico (das Logische), pela primeira vez tematizado na Ciência da Lógica, constitui o conteúdo da filosofia toda, desde que ele seja entendido não como um mero aspecto (ainda que fundamental ou primeiro) do sistema, mas como a autoatividade de uma forma absoluta, cujo caráter de absolutidade decorre do fato de ela não ter nenhum conteúdo (formal ou material) fora de si, porque cada conteúdo é algo de determinado, que a forma (o determinante) tem de dar a si mesma, isto é, produzir para si, em virtude de uma atividade de autodiferenciação e de mediação das diferenças. Justamente a maneira de conceber a produtividade da forma é o fator que diferencia o idealismo transcendental do idealismo absoluto de Hegel. A análise que se segue visa a esclarecer minha tese, desenvolvendo quatro facetas do conceito operativo $^{10}$ de "ausência de pressuposição", cada uma das quais constitui, em conjunto com as outras, o critério de cientificidade da filosofia especulativa.

tura hegeliana de Kant: (i) fixar Kant em um procedimento dicotômico; (ii) o reconhecimento da experiência como único sentido de conhecimento; (iii) a tese do idealismo subjetivo. Cf. FERRARIN, A. "Il pensare e l'io. Hegel e la critica di Kant". Roma: Carocci, 2016. pp. 171-234 (especialmente pp. 188-203).

9 Cabe assinalar que a tradução "ausência de pressuposição", proposta por Meneses para a ocorrência do termo Voraussetzungslosigkeit no $\$ 78$ da Enciclopédia, tem a desvantagem de sugerir um ilusório estado de coisas (ilusório porque, já antes de Heidegger e Gadamer, Hegel reconhece que nenhum filósofo pode empreender a especulação a partir de um vazio de pressuposições) em vez de uma atividade, acabando por negligenciar a ação negativa que está envolvida no filosofar, ação que consiste no reconhecimento de que as pressuposições de todas as crenças e de todas as ciências finitas são fatos que o sujeito filosofante não pode mais tomar como óbvios nem assumir como critérios já estabelecidos do saber.

10 Falando em "conceito operativo", quero dizer que a "ausência de pressuposição" não é uma categoria, isto é, não é um conceito temático determinado dentro da ciência, mas antes o procedimento metodicamente articulado voltado a solucionar, de modo coextensivo ao sistema, o problema seguinte: como é possível a filosofia enquanto ciência da liberdade? 


\section{A imanência da realidade ao pensar}

O primeiro aspecto da "ausência de pressuposição" é a imanência da realidade ao pensar. Hegel defende esse tipo de imanência quando fala de "pensar objetivo" $"$. Com isso, ele quer dizer um pensar que não é primacialmente o ato da consciência, mas o fundamento de tudo, a atividade interna que estrutura todas as coisas (os entes materiais) assim como nossos pensamentos subjetivos sobre as coisas. O caráter objetivo do pensar não deve ser de antemão contraposto a uma esfera apenas subjetiva de conteúdos mentais. Antes, a objetividade em questão possui duas acepções.

Em um sentido mínimo, de tipo metodológico, objetividade significa libertação do reino das opiniões, reino delimitado pela multiplicidade cambiante das representações e dos interesses de indivíduos que não sabem enxergar um palmo adiante do nariz, quer dizer, além da particularidade e da acidentalidade dos próprios preconceitos. Objetivo é o pensamento capaz de produzir um conhecimento imparcial, transindividual, de modo que a determinação atribuída por um indivíduo a um objeto é susceptível de ser verificada por outros indivíduos como algo que advém efetivamente do objeto.

Em um sentido máximo, de tipo metafísico, a objetividade é o ser em si e para si do pensar, a saber, o fato de que o pensar é uma atividade que não tem alguma condição de possibilidade fora de si, não depende de algum fundamento externo ou dado, e por isso, longe de ser uma entidade, é um processo independente de todo e qualquer substrato; antes, o próprio pensar é o fundamento da própria divisão em ser e pensar subjetivo, ou, em outras palavras, da cisão em um pensar inconsciente (pensar em si), que forma a inteligibilidade objetiva das coisas, e em um pensar consciente de si (pensar para si), que articula a dita inteligibilidade nos pensamentos dos seres humanos (espírito finito), na medida em que estes desenvolvem sua humanidade, isto é, passam progressivamente de um estágio natural-instintivo para um estágio espiritual ou inteligente, no qual o pensar objetivo chega a refletir sobre si mesmo e a descobrir a lógica de sua própria processualidade. ${ }^{12}$

Cf. HEGEL, G. W. F. (2016): “Esse pensar objetivo é, pois, o conteúdo da ciência pura” (p. 52); "Pensar é uma expressão que atribui a determinação nela contida preferencialmente à consciência. Mas, na medida em que é dito que o entendimento, que a razão, estão no mundo objetivo, que o espírito e a natureza têm leis universais segundo as quais sua vida e suas alterações se fazem, então admite-se que as determinações do pensar igualmente têm valor e existência objetivos". (p. 53)

12 Para um esclarecimento e uma problematização da concepção hegeliana do pensar objetivo, remeto especialmente a: FERRARIN, A. "Il pensare e l'io. Hegel e la critica di Kant". Roma: Carocci, 2016, pp. 71-83. De acordo com o autor italiano, o segundo sentido de pensar objetivo tem a ver com um "pensar não humano" (p. 71), que abrange tanto um pensar subumano ou inconsciente quanto um pensar divino ou transumano (p. 77). A respeito do caráter transumano, o autor tem a suspeita de que se trataria de um impasse, ao qual acabamos sendo conduzidos por uma leitura desviante do pensar objetivo, isto é, por uma leitura "realista" da ideia absoluta, que risca de subordinar o pensar subjetivo a um movimento em si independente do ser humano. A meu ver, essa suspeita se dissolve se cuidamos de incluir no sentido forte ou metafísico do pensar objetivo a consideração do papel do espírito finito. Com isso, fica o desafio da 
Convém notar que Hegel usa dois termos técnicos para designar o princípio interno e a efetivação do pensar objetivo: "conceito" e "ideia". Ambos têm de ser depurados de conotações psicológicas ou transcendentais ou vagamente platônicas. $\mathrm{O}$ conceito não está contraposto às coisas como uma reprodução mental (ou linguística) delas, nem é uma regra de unificação das representações produzida pela assim chamada faculdade de pensar. $O$ conceito não é nem um agente divino que rege uma totalidade de entes que permanecem externos a ele nem um substrato ou um fundamento subjacente ao processo do real. "Conceito" é o nome que está pelo princípio dinâmico de todo o pensável e de todo o efetivo. Esse princípio não é uma causa separada de seus efeitos, mas antes um universal que se manifesta integralmente nas modalidades particulares e singulares de sua atividade. A "ideia", formalmente, nada mais é do que a efetivação do conceito na realidade determinada de suas manifestações, que têm lugar dentro do âmbito dos pensamentos puros da Lógica e no âmbito real das formações concretas da natureza e do espírito. O idealismo absoluto de Hegel, portanto, é o estudo da ideia enquanto processo de autoexteriorização (Selbstentäußerung) sem substratos e sem restos da atividade do conceito, ao mesmo tempo único (por ele não ser delimitado por outro) e plural (por ele ter de se articular em conceitos determinados). ${ }^{13}$

A filosofia idealista de Hegel é uma filosofia da imanência absoluta, porque ela entende a distinção entre ser e pensar subjetivo como uma divisão interna ao próprio pensar em sentido objetivo. Ser e pensar não são de antemão termos contrapostos, mas termos relacionais, que chegam a ganhar significado opositivo somente em virtude da função explanatória que tal oposição vem a desempenhar dentro do movimento de autoexteriorização do conceito. Uma vez que uma filosofia da imanência não admite a possibilidade de um observador externo, o idealismo tem de envolver tanto o princípio quanto a compreensão do princípio, isto é, tanto o ser em ato do processo quanto o entendimento teórico deste último. O idealismo está associado a uma peculiar ontologia dos processos, que permite detonar um conjunto de dilemas que tendem a prender nossa interpretação de Hegel em outras tantas camisas de força, ou seja, em impasses motivados por preocupações, em última instância, externas ao sistema, tais como as questões de se a teoria hegeliana do ser seria monista ou pluralista, normativa ou descritiva, fundacionalista ou holista.

leitura metafísica do pensar objetivo, a saber: como é possível elaborar a justificação filosófica da unidade entre um pensar consciente ou subjetivo e um pensar impessoal consistente na inteligibilidade objetiva das próprias coisas? Evidentemente, a leitura "realista" acima mencionada, segundo a qual a ideia absoluta seria um agente único e acabado por trás de cada processo, não é um caminho viável para essa tarefa.

13 A autoexteriorização não deve ser entendida como a "alienação" de uma unidade simples preexistente. Para uma contribuição sobre como entender a união do movimento de exteriorização e de interiorização da ideia absoluta, remeto a um trabalho meu: ORSINI, F. "On Hegel's Idea of a Logical Ontology". In: Anais do IX Congresso internacional de Filosofia da UNICENTRO, 2015: http://anais.unicentro.br/conifil/ pdf/ixv9n1/72.pdf 
O termo "ontologia", embora possa de imediato sugerir a ideia de que o pensamento seria um tipo de entidade a ser classificada no catálogo do universo ou um processo que teria seu fundamento em um actus essendi preexistente, encontra-se aqui empregado de modo bastante livre, em razão da ampliação e das evoluções que sua semântica recebeu, nas mais variadas vertentes da filosofia do século XX. Em um sentido básico, a ontologia é o esforço de entender com que nos comprometemos ao dizermos que algo é, que é assim ou assado, que é quantificável, que existe ou não, que é efeito ou causa de algo diferente, que é universal ou particular, etc. Todavia, cabe lembrar que "ontologia", para Hegel, é o nome de uma disciplina cujos contornos históricos e formais correspondem a um momento determinado (o momento dogmático) da história da metafísica (a metafísica escolástica), assim como a uma possibilidade tipizada (sempre abstratamente presente) da posição ingênua do pensamento a respeito da objetividade. Na medida em que a filosofia dialético-especulativa rompe com essa ontologia, reconstruindo a priori (isto é, de modo puramente autodesenvolvimental) o conteúdo das tradicionais doutrinas das categorias, pode-se afirmar que o idealismo absoluto é uma lógica do pensar que pensa a si mesmo e, simultaneamente, uma teoria do ser enquanto ser pensado. Justamente a reflexividade do pensar objetivo é o que impulsiona a ontologia hegeliana para além das pressuposições da ontologia pré-kantiana. ${ }^{14}$

\section{Ceticismo e dialética}

O segundo aspecto da "ausência de pressuposição" remete à atitude cética, que somente pode justificar a visão idealista da realidade efetiva enquanto um todo autodiferenciado. O ceticismo que Hegel julga próprio a seu projeto filosófico busca dissolver as aporias do representacionalismo que impregnam a epistemologia moderna por meio de uma coordenação de três linhas de ação crítica.

Em primeiro lugar, vale a nítida distinção entre ceticismo moderno de tipo humiano e o ceticismo antigo de tipo pirrônico ${ }^{15}$. Essa distinção tem a ver com

14 Para um aprofundamento do controverso tema do sentido da reconstrução hegeliana da ontologia, com uma discussão detalhada do status quaestionis, remeto a: ${ }^{\star \star \star}$ ORSINI. F. "Il problema dell'ontologia nella Scienza della logica di Hegel” (Tese de doutorado, Universidade de Padova, UNIPD, Itália, 2014).

15 Cf. HEGEL, G. W. F. (1995), §39, Observação, p. 107. Sobre o ceticismo como caráter da "epistemologia" em um sentido hegeliano, destaca-se FORSTER, M. "Hegel and Skepticism". Cambridge: Harvard University Press, 1989, pp. 96-180. Para uma análise da relevância do ensaio juvenil de Hegel "Sobre a relação da filosofia com o ceticismo" (1802), leiam-se: VERRA, V. "Hegel e lo scetticismo antico: la funzione dei tropi”. In: GIANNANTONI, G. (Org.) Centro di Studio del pensiero antico del CNR. ATTI DEL CONVEGNO DI ROMA SU LO SCETTICISMO ANTICO, 5-8 novembre 1980, 2 voll. Napoli, Bibliopolis, 1981, v. I, pp. 4960; CHIEREGHIN, F. "Il Parmenide di Platone alle origini della dialettica hegeliana". Verifiche, Trento, 3-4, XXIV (1995), pp. 243-272; VIEWEG, K. "Philosophie des Remis. Der junge Hegel and das ,Gespenst des Skeptizimus'”. München: Fink, 1999, pp. 113-181; MARTIN, L. F. "A presença do ceticismo na filosofia do jovem Hegel”. In: SMITH, Plínio Junqueira; SILVA FILHO, Waldomiro (Orgs.) "Ensaios sobre o ceticismo". São Paulo: Alameda, 2007, pp. 153-171.; TRISOKKAS, I. "Pyrrhonian Skepticism and Hegel's Theory of 
o critério de justificação de nossas pretensões de verdade. $O$ empirismo põe o critério na experiência sensível e nos fatos de consciência, ao passo que o ceticismo grego revela que a experiência é um fundamento altamente instável. O método elaborado pelos céticos era o método de equipolência, segundo o qual a cada tese e a cada argumento pode-se contrapor uma tese ou um argumento dotado de igual força. Os dez tropos de Enesidemo, direcionados contra o senso comum, e, mais ainda, os cinco tropos de Agripa (diversidade, regresso infinito, relação, hipótese, circularidade viciosa ou dialelo), direcionados contra os filósofos dogmáticos, são reconduzidos por Hegel a meros conceitos de reflexão, os quais têm efeitos diferentes, dependendo de se são dirigidos contra o dogmatismo ou contra a filosofia especulativa. O tratamento do ceticismo pirrônico mostra uma ambiguidade relevante. Por um lado, Hegel não pretende rejeitá-lo, pois reconhece sua função crítica com respeito ao dogmatismo, que é o modo de filosofar que absolutiza, sem investigá-los, princípios finitos em detrimento de outros. Por outro lado, Hegel não endossa completamente o ceticismo pirrônico, não só porque este último tem uma finalidade externa à teoria (a tranquilidade do ânimo), mas também porque o ceticismo é apenas o lado negativo ou destruidor da filosofia. Se ele fosse deixado a si mesmo, isolado da especulação, o ceticismo conduziria ao quietismo ou a um assalto infrutífero à filosofia como tal.

Em segundo lugar, o ceticismo chega a coincidir com a dialética em dois momentos diferentes e igualmente cruciais para a fundamentação do idealismo: na Fenomenologia do Espírito (1807) e na Ciência da Lógica (1812-1816). Na obra de Jena, estamos diante de um processo em que a consciência natural ou ordinária é como que forçada a subverter suas certezas a fim de chegar ao ponto de vista do saber científico. Esse caminho é descrito por Hegel como um "ceticismo que se consuma (sich vollbringender Skeptizismus)", ${ }^{16}$ porque a consciência, por meio do critério gerado pela medida de seu suposto saber, tem de ser conduzida a examinar e a, no final, subverter cada figura de si mesma, na medida em que se encontra dominada pela oposição espontânea entre o lado do saber e o lado da verdade ${ }^{17}$. Na obra de Nuremberg, que pretende desenvolver o conceito de ciência desde dentro do pensar como tal, o momento cético e o dialético são idênticos, enquanto a presença ativa da negação determinada abala a pretensão de cada determinação de se apresentar como uma definição exaustiva do absoluto. Uma passagem da Enciclopédia expressa de modo bem

Judgment”. Leiden: Brill, 2012, espec. pp. 43-70.

16 Cf. HEGEL, G. W. F. “Theorie Werkausgabe in zwanzig Bänden” (=TW). Moldenhauer E., Michel M. (Orgs.) Frankfurt am Main, Suhrkamp, 1969, Phenomenologie des Geistes, v. 3: TW 3/72.

17 Para uma leitura da Fenomenologia à luz do problema do ceticismo, veja: HEIDEMANN, D. "Hegel on the Nature of Scepticism". Bulletin of The Hegel Society of Great Britain, Cambridge, Cambridge University Press, 63, pp. 80-99, 2011. 
claro em que consiste a integração do ceticismo ao momento dialético da razão: "As formas-de-pensamento devem ser consideradas em si e para si; são o objeto e a atividade do objeto mesmo; examinam-se a si mesmas, e devem determinar nelas mesmas seu limite e mostrar sua falha". ${ }^{18}$

Em terceiro lugar, o momento dialético não pode se desvencilhar do momento positivo-racional ou especulativo. Já vimos que o verdadeiro ceticismo não se identifica completamente com o ceticismo grego, pois este último simplesmente subverte o dogmatismo a fim de chegar à ataraxia mediante a suspensão do juízo, enquanto o ceticismo hegeliano precisa unir a atividade das formas do pensamento com a crítica delas, com vistas à apresentação do processo do conhecer conceituante. $\mathrm{O}$ verdadeiro ceticismo, então, como unidade de crítica e de apresentação das formas ${ }^{19}$, desmascara a nulidade ou inverdade do finito (não importa como se queira denominá-lo: mundo externo, pensamento subjetivo, temporalidade, etc.) e, ao mesmo tempo, manifesta o resultado afirmativo que decorre da dissolução do finito. Enquanto o finito é um momento unilateral do infinito, o ceticismo deve resultar em um conteúdo infinito, ou seja, verdadeiro. Por causa disso, dialética e especulação não são instrumentos para a reflexão externa sobre dados âmbitos de pretensões de verdade, mas antes momentos internos da razão, a qual nada mais é do que o pensar objetivo que determina a si mesmo de modo livre (isto é, sem pressupor algum âmbito dado ou alguma autoridade externa). Isso significa que o pensar, se adequadamente compreendido, não tem um conteúdo verdadeiro, mas o produz por meio de si mesmo, já que a verdade (Wahrheit) só existe como processo de verificação (Bewährung) e o banco de prova da verificação ou justificação da verdade é a integração do ceticismo ao movimento de mediação do conceito $^{20}$.

\section{Circularidade}

A integração do potencial epistêmico-crítico do ceticismo radical ao alcance ontológico do idealismo faz com que a única figura rigorosa da ciência adquira a forma de um sistema da razão. Longe de ser o emblema de todo e qualquer dogmatismo pretensioso, o sistema é para Hegel a única maneira do filosofar científico, porque só o sistema permite encarar e rejeitar todas as

HEGEL, G.W.F. "Enciclopédia das Ciências Filosóficas em Compêndio (1830), v. I, A Ciência da Lógica”. Tradução de Paulo Meneses. São Paulo: Loyola, 1995. §41 Adendo 1, p. 109.

19 Sobre esse tema, remeto ao clássico estudo de THEUNISSEN, M. "Sein und Schein. Hegels Logik und ihre kritische Funktion". Frankfurt a.M: Suhrkamp, 1980.

20 HEGEL, G. W. F. (1995): “a verdade, justamente como tal, tem de verificar-se, verificação que aqui, no interior do lógico, consiste em que o conceito se mostre como o que é mediatizado por si mesmo e consigo mesmo, e por isso, ao mesmo tempo, como o verdadeiramente imediato" (§83, Adendo, p. 169). 
objeções do assim chamado Trilema de Agripa. (i) O tropo cético do regresso ao infinito na cadeia das determinações é detonado pelo fato de que o sistema não é um agregado, mas uma totalidade, dentro da qual as partes têm sentido por meio da relação de cada uma com todas as outras, e vice-versa, o todo tem sentido mediante a simultânea união e divisão de suas partes. (ii) $\mathrm{O}$ tropo da escolha arbitrária do fundamento do sistema também é solapado pelo próprio conceito de sistema, porque o único fundamento do sistema é a articulação orgânica de seus membros, não a primazia de uma parte sobre as outras e ainda menos o recurso a uma base de sustentação externa ao sistema. Se uma livre escolha deve entrar em cena, essa tem de concernir à resolução de filosofar por parte do sujeito finito, não às leis da lógica de funcionamento do próprio sistema. (iii) $\mathrm{O}$ tropo da circularidade viciosa ou petitio principii só teria êxito se assumíssemos que a ideia é uma estrutura subjacente que preexiste ao processo de apresentação que deveria verificá-la, mas já vimos quão errônea é essa assunção.

O sistema configura uma circularidade virtuosa, isto é, um ciclo que produz e reproduz a si mesmo e, por isso, não é vulnerável às objeções céticas mencionadas. Circularidade e sistema são até sinônimos, porque ambos trazem consigo uma crítica à concepção de uma dedução unilinear em que o ser seria derivado a partir do pensar ou vice-versa, de acordo com uma sequência de passos numericamente definida que separa o início e o fim do processo. O sistema se apresenta de modo duplo: tanto do ponto de vista do impulso da razão a fazer-se real (sistema da efetividade) quanto do ponto de vista do impulso da razão a saber de si em seu fazer (sistema da filosofia). Segundo o primeiro ponto de vista, o sistema é a articulação de elemento lógico, natureza e espírito. Conforme o ponto de vista do saber, o sistema é a conexão conceitual de lógica, filosofia da natureza e filosofia do espírito. A relação entre o primeiro e o segundo ponto de vista, sendo uma relação imanente ao pensar objetivo, não é aquela de um mero espelhamento ou de genérica fundação, mas, a rigor, conforme sugerido pelo segundo Prefácio (1831) à Ciência da Lógica, uma relação de progressiva explicitação ou conscientização do impulso racional.

A circularidade do sistema significa que o ser objetivo e o pensar subjetivo são os polos de um processo inesgotável, isto é, sem início e sem término, um processo que subverte o dualismo entre eternidade e tempo e rompe com a pretensão de autossuficiência (epistemológica ou ontológica) de qualquer determinação de pensar ou de qualquer caminho privilegiado de acesso ao sistema. Do ponto de vista da história da filosofia, a circularidade oferece a formulação hegeliana do imanentismo de Espinosa e, ao mesmo tempo, a tentativa de compreender a subjetividade em uma maneira não primariamente consciencial, à qual, para Hegel, ainda ficariam presos os projetos de idealismo 
transcendental de Kant e de Fichte. A subjetividade que Hegel tem em vista é o momento culminante do pensar objetivo, ou seja, trata-se de um processo de autoconhecimento inerente ao ser. É isso que Hegel chama de "espírito", que não pode ser entendido ao aceitarmos como verdadeira ou como irredutível a contraposição entre ser e saber, entre sujeito e objeto, entre Eu e não-Eu. Circularidade, sistema e subjetividade formam o horizonte absoluto de imanência de um processo sem agente, sem legislador, ao qual, por isso, não se pode aplicar nenhuma concepção instrumental de regra, pois esta pressupõe o persistir de uma exterioridade recíproca entre agente, ação, instrumento de ação e avaliação do êxito da ação por meio de um ou mais agentes diversos do primeiro.

Longe de marcar o fechamento do sistema em uma suposta teleologia incondicionada (isto é, solta da ligação com o condicionado e dirigida a uma meta preestabelecida), a circularidade destrói a ilusão de um ponto de parada do sistema, onde este último pareceria poder descansar em uma configuração definitiva de si mesmo ${ }^{21}$. Decerto, o sistema hegeliano não é o que, em uma linguagem contemporânea, denominar-se-ia um sistema aberto, no sentido de ser indefinidamente modificável em consequência da troca de materiais e de energia com sistemas externos ao pensar objetivo. Para Hegel, a energia operante no real constitui um único sistema, mas esse sistema, em virtude de seu aspecto idealista anteriormente comentado, é um sistema processual, que não pode se fechar em algum elemento (nem que seja o elemento mais universal) sem ter de romper com ele, de modo que em cada elemento do sistema está em jogo a verdade do todo, o qual tem que se configurar recursivamente como um "círculo de círculos"22.

\section{Subversão da concepção comum de abstrato e concreto}

Um sistema de ceticismo consumado resulta na subversão da convicção do senso comum de que apenas o palpável é o modo mais concreto do ser. As três modalidades de apresentação da ideia (isto é: elemento lógico, elemento natural, elemento espiritual) fornecem o sistema de referência para subverter a acepção ordinária de "abstrato" e "concreto", de modo a poder entendê-los de maneira diferente dentro do processo da ideia. "Abstrato" e "concreto" não indicam aquilo que se encontra respectivamente dentro ou fora da mente, mas antes estágios mais ou menos desenvolvidos ao interior de cada processo de determinação da ideia. Nesse sentido, a concretude do elemento lógico tem a ver com a crescente intensificação de relações conceituais que as categorias 
ganham enquanto a ciência progride do ser para a essência e, a partir desta, para o conceito. A concretude do elemento real (natural ou espiritual) vai além disso, porque ela envolve uma diferença e até um contraste entre inteligibilidade e exterioridade, entre atividade e passividade, distinções reais que ainda não afetam as diferenças exclusivamente ideais ou inteligíveis do pensar que pensa a si mesmo. Essa idealização requer que o pensar abstraia a si mesmo, quer dizer, isole o exame de suas próprias formas do problema de por que e como elas encontram sua realização no mundo efetivo.

Abstrato e concreto, portanto, precisam de dois níveis de tematização. $\mathrm{O}$ primeiro nível é a consideração da progressiva riqueza de determinações de pensar que se realizam na transição do elemento lógico para o elemento natural e, então, desse para o elemento espiritual ${ }^{23}$. Aqui, o lógico é o elemento abstrato e primeiro (no sentido de ele ser o ponto a partir do qual o concreto pode ser reconstruído geneticamente), enquanto a natureza e o espírito constituem o elemento realmente concreto, o qual, por sua vez, tem de reconhecer a diferença qualitativa entre a concretude inconsciente da natureza e aquela progressivamente consciente do espírito. O segundo nível é a tematização que recai ao interior de cada elemento, a qual tem de proceder da determinação mais abstrata (isto é, mais pobre de determinações) para a determinação mais concreta (isto é, compreensiva das determinações anteriores e capaz de determinar a si mesma). A sinergia entre os dois níveis permite argumentar que, para Hegel, a pergunta sobre se o abstrato é o fundamento do concreto ou vice-versa é mal colocada, porque abstrato e concreto não devem ser entendidos como fundamentos um do outro, mas antes como momentos de de um todo em desenvolvimento, que Hegel denomina "conceito". A efetivação do conceito em formas de ser cada vez mais adequadas reconfigura radicalmente a concepção tradicional da verdade como correspondência de uma asserção a um estado de coisas, porque a verdade num sentido especulativo deixa de ser o predicado de um conhecimento capaz de espelhar uma realidade externa a si.

Uma vez que os estágios do processo da ideia são eles mesmos processos, por eles envolverem um desenvolvimento do abstrato para o concreto, o processo global é um processo de processos, no interior do qual a avaliação do grau de verdade de cada estágio está em função do grau de libertação do espírito para o próprio autoconhecimento. Não há verdade e sentido especulativo sem autoconhecimento. Já que o espírito não é a rigor um fundamento do processo da ideia absoluta (porque ele não é substrato, não é condição, não é

23 Para um exame dos problemas envolvidos na transição do elemento lógico para o elemento natural, remeto a um trabalho meu: ${ }^{\star \star *}$ ORSINI, F. "Che cosa intuisce l'idea assoluta? Sulla logica hegeliana della creazione”. In: LIMA, Francisco Jozivan Guedes de; ARAÚJO, Gerson Albuquerque de (Orgs.) "Filosofia Prática, Epistemologia e Hermenêutica". Porto Alegre: Editora Fi, 2016, p. 229-266. 
regra, nem agente organizador do processo), mas o estágio mais concreto de tal processo, o critério da verdade não é a adequação do processo a algo externo, mas a imanência do objeto de consideração ao modo de sua produção, a sua gênese. A verdade não decorre da disponibilidade de critérios de correspondência com um âmbito externo ao processo de conhecimento, mas antes consiste na dinâmica do modo de produção do conhecimento e, simultaneamente, do objeto conhecido. Diferentemente do que acontece na theōria de Aristóteles, o objeto de conhecimento não preexiste a seu conhecimento e, se se quer admitir a fala tradicional de correspondência, os termos que se correspondem não são a alma individual e um dos múltiplos gêneros de ser independentes do pensar, mas o conceito e sua realidade determinada. Ao defender o idealismo absoluto, Hegel se apropria da convicção espinosana de que o verdadeiro é índice (ou critério) de si e do falso.

Por fim, cada uma das modalidades da ideia adquire um significado diferente em relação ao modo cada vez diferente no qual os seres humanos (isto é, o espírito finito) se orientam no atravessamento do caminho sistemático que conecta lógico, natureza e espírito. Especialmente os três silogismos finais da filosofia, que concluem a primeira (1817) e a terceira (1830) versões da $E n$ ciclopédia, mostram que a transição linear do elemento lógico para o espírito por meio da natureza é apenas o ponto de vista mais imediato ${ }^{24}$ entre os três caminhos que precisamos empreender para nos reconhecermos como espírito infinito encarnado no tecido de relações que articulam o abstrato e o concreto. O ponto de vista mais adequado é o do terceiro silogismo, que expressa o esforço de compreender o duplo processo de cisão e unificação do primeiro e do segundo silogismo, a saber, respectivamente, do sistema objetivo, necessário e acabado independentemente da contribuição do sujeito filosofante, e do sistema subjetivo, isto é, do sistema apropriado pelo ponto de vista do espírito finito, histórico e reflexivo.

\section{Conclusões}

A reconstrução dos aspectos entrelaçados do método da Voraussetzungslosigkeit do pensar objetivo permite tirar algumas conclusões relevantes para a compreensão do projeto filosófico do idealismo de Hegel.

Em primeiro lugar, a ausência de pressuposições só pode se confirmar o ponto de vista imediato do primeiro silogismo indica a situação na qual o sujeito filosofante funciona ainda, apesar do resultado alcançado pela Fenomenologia do Espírito, como consciência, esquecendo a si mesmo perante seu objeto (p. 244). Sob esse aspecto, o primeiro silogismo configura uma espécie de contemplação passiva de um processo objetivo, isto é, independente do pensar humano (p. 243). 
enquanto prova científica através da subversão das certezas do senso comum sobre o que seria subjetivo ou objetivo, abstrato ou concreto.

Em segundo lugar, a prova da imanência é científica na medida em que mostra a necessária imbricação entre o aspecto ontológico (a imanência do real ao pensar) e o aspecto epistemológico (ceticismo dialético-especulativo) do sistema.

Em terceiro lugar, o sistema não é de algum modo reduzível a essa ou àquela versão da apresentação da Enciclopédia, porque esta obra apenas proporciona um auxílio didático para a exposição do sistema da filosofia. Além do fato de que a sistematicidade do saber não esgota aquela do real, o próprio saber não pode apreender o real de uma só perspectiva, mas unicamente pela organização progressivamente concreta dos três silogismos do conceito de filosofia, os quais apontam outras tantas modalidades de leitura da Enciclopédia.

\section{Referências}

BRANDOM, R. "Some Hegelian Ideas of Note for Contemporary Analytic Philosophy”. Hegel Bulletin, v. 35, n. 1, pp. 1-15, 2014.

CHIEREGHIN, F. "Il Parmenide di Platone alle origini della dialettica hegeliana". Verifiche, Trento, 3-4, XXIV, pp. 243-272, 1995.

CHIEREGHIN, F. "Mort et transfiguration de la métaphysique chez Hegel". In: KERVÉGAN, J. F.; MABILLE, B. (Orgs.) Hegel au présent. Une releve de la métaphysique? Paris: CNRS Éditions, 2012. pp. 51-64.

FERRARIN, A. "Il pensare e l'io. Hegel e la critica di Kant”. Roma: Carocci, 2016.

FORSTER, M. "Hegel and Skepticism”. Cambridge: Harvard University Press, 1989. GERAETS, T. "Les trois lectures philosophiques de l'Enciclopédie ou la realisation du concept de la philosophie chez Hegel". Hegel-Studien, Hamburg, Meiner, 10, pp. 231-254, 1975.

HEGEL, G. W. F. “Ciência da Lógica”. A Doutrina do Ser. Petrópolis: Vozes, 2016. HEGEL, G. W. F. "Enciclopédia das Ciências Filosóficas em Compendio (1830), Vol. I, A Ciência da Lógica". São Paulo: Edições Loyola, 1995.

HEGEL, G. W. F. "Theorie Werkausgabe in zwanzig Bänden (=TW)" In: MOLDENHAUER, E.; MICHEL, M. (Orgs.) Frankfurt am Main, Suhrkamp, 1969. (Phenomenologie des Geistes, Vol. 3)

HEIDEMANN, D. "Hegel on the Nature of Scepticism". Bulletin of The Hegel Society of Great Britain, Cambridge, Cambridge University Press, 63, pp. 80-99, 2011.

KERVÉGAN, J. F. “Hegel e o hegelianismo”. São Paulo: Edições Loyola, 2008.

MARTIN, L. F. "A presença do ceticismo na filosofia do jovem Hegel”. In: SMITH, Plínio Junqueira; SILVA FILHO, Waldomiro (Orgs.) "Ensaios sobre o ceticismo". São Paulo: Alameda, 2007. pp. 153-171.

NUZZO, A. (Org.) "Hegel and the Analytic Tradition". New York: Continuum, 2009. ORSINI, F. "On Hegel's Idea of a Logical Ontology". In: IX CONGRESSO INTERNACIONAL DE FILOSOFIA DA UNICENTRO, Anais... 2015: Disponível em: 
$<$ http://anais.unicentro.br/conifil/pdf/ixv9n1/72.pdf $>$.

ORSINI, F. "Che cosa intuisce l'idea assoluta? Sulla logica hegeliana della creazione". In: FRANCISCO JOZIVAN GUEDES DE LIMA; GERSON ALBUQUERQUE DE ARAÚJO NETO (Orgs.) "Filosofia Prática, Epistemologia e Hermenêutica". Porto Alegre: Editora Fi, 2016, p. 229-266.

REDDING, P. "Analytic Philosophy and the Return of Hegelian Thought". Cambridge: Cambridge University Press, 2007.

REDDING. P. "The Relation of Logic to Ontology in Hegel”. In: HAAPARANTA, L.; KOSKINEN J. (Orgs.) "Categories and Being. Essays on Metaphysics and Logic". London- New York: Oxford University Press, 2012. pp. 145-166.

THEUNISSEN, M. "Sein und Schein. Hegels Logik und ihre kritische Funktion". Frankfurt a.M: Suhrkamp, 1980.

TRISOKKAS, I. "Pyrrhonian Skepticism and Hegel's Theory of Judgment". Leiden: Brill, 2012.

VERRA, V. "Hegel e lo scetticismo antico: la funzione dei tropi". In: GIANNANTONI, G. (Org.) Centro di Studio del pensiero antico del CNR. ATTI DEL CONVEGNO DI ROMA SU LO SCETTICISMO ANTICO, 5-8 novembre 1980, 2 voll. Napoli, Bibliopolis, 1981, v. I, pp. 49-60.

VIEWEG, K. "Philosophie des Remis. Der junge Hegel and das, Gespenst des Skeptizimus"”. München: Fink, 1999. 
